\title{
Action Research in Vietnamese Schools as a Tool for Teacher Professional Development
}

\author{
Nguyen Hoang Doan Huy (Corresponding author) \\ Institute of Educational Research \\ Hanoi National University of Education, Vietnam \\ Tel: 84-964-780-188Ｅ-mail: nguyenhoangdoanhuy@gmail.com \\ Nguyen Ngoc Quynh Anh \\ School of Public Health and Preventive Medicine \\ Monash University, Australia \\ Tel: 61-411-233-540Ｅmail: ngoc.a.nguyen@monash.edu \\ Bui Thanh Dieu \\ Psychology and Education DepartmentThe University of Danang \\ University of Education, Vietnam \\ Tel: 84-983-323-231Ｅ-mail: dieuthanh02@gmail.com
}

Received: April 20, 2018 Accepted: June 12, 2018 Published: July 18, 2018

doi:10.5296/ire.v6i2.13037ＵRL: http://dx.doi.org/10.5296/ire.v6i2.13037

\begin{abstract}
Educational research skill which is considered as a component of professional development competence of Vietnamese teachers, is an indicator of the Vietnamese teacher professional competences standards approved by the Ministry of Education and Training. Many activities have been organizing to enhance the teacher research skills in Vietnamese schools. The article deals with the possibilities of the incorporation of action research - a form of educational research - into teacher professional development; shows a relative status of Vietnamese teachers' competence on action research; and thus, proposes some orientations on promoting
\end{abstract}


teacher professional development through developing action research skills in Vietnamese schools.

Keywords: teacher research, educational research, action research, teacher professional development, enhance teacher competences

\section{Introduction}

\subsection{Teacher Action Research}

Confusion can be caused by the fact that in education, the terms action research, teacher research, and practitioner inquiry (or practitioner research) are often used almost interchangeably. In fact, however, there are important differences between action research and teacher research. Teacher research is commonly used to describe all kinds of school- and classroom-based research conducted by practitioners. It has been defined as "inquiry that is intentional, systematic, public, voluntary, ethical, and contextual". Teacher research as a general term embraces many methodologies and many situations (Joseph \& Russell, 2011). In contrast, action research in its strict sense refers to research activities that use a cyclical, action reflection model to investigate and attempt to make change in an organization, for example, a whole school. To simplify, all action research conducted by practitioners can properly be termed teacher research, but not all teacher research can properly be labeled action research.

Action research was initiated in the 1940s by Kurt Lewin and modified by educators later. According to Kemmis and Mc Taggart (1992), action research was absorbed into education from the earliest beginnings of the development of Lewin's ideas, with the latter working alongside teachers in action research programs. Action research in education is seen as a means of closing the so-called "theory-practice gap". Power for change lies in the use of action research to develop a critically reflexive practice in which theory and practice are integrated and theory emerges from practice. Elliot (1991) views action research as a form of reflexive practice and argues that it can become a "cultural innovation".

\subsection{Teacher Professional Development}

The waves of education reforms in global context and in Vietnam in particular have redefined the role of teachers in modern schools with the implementation of four basic roles in society, as including: the educator, the socio-cultural expert; the life-long learner; and the researcher (Nguyen Thi Kim Dung, 2015). Therefore, teachers should be considered as researchers to address their own educational realities, develop the curriculum and the school activities, contribute to the development of their profession... via observing, analyzing, reflecting and summing up the experiences from the educational reality and the professional activities of themself as well as their collegues in schools.

Teacher professional development capacity along with other core competencies of the teacher professional standards is one of the issues that need to be researched and explored in the appropriate way to form and develop. This helps teachers improve their professional performance. Many educational researchers have identified the characteristics and ways in 
which teachers can develop professional competences effectively (David J. Cooper, 2014, cited from Darling-Hammond, 1997; Darling Gerstein, Chard, and Baker, 2000; IASA, 1996; Joyce and Showers, 1988; Showers, Joyce, and Bennett, 1987; Sparks, 1983; Sparks and Hirsch, 1997). Besides of self-study, thus, educational research activities conducted by teachers will not only help teachers develop their professional competencies but also contribute to improving the educational quality of their schools. Many studies have shown the effectiveness of teachers' engagement in researching their own teaching practices, as well as pointing to the very same teaching practices that can be effective ways to improve and develop the profession of the teacher itself. Not only that, it is the view that the teacher as an educational practitioner has pointed out that only through research, in the process of constantly learning and solving problems related to teaching and learning, teachers themselves can become knowledge builders (Cabaroglu 2014).

\subsection{Applying Action Research into Teacher Professional Development}

Recently, the term "teacher-as-researcher" has been mentioned extensively in the field of education. There has been a growing recognition in the international education community over the last decade of the powerful role of teachers as researchers (Gray \& Campbell, 2002, cited from Darling-Hammond, 1999; Gore \& Morrison, 2000; Kemmis, 2001; Roger, 2002). There is growing evidence that there is a positive impact on teachers' personal and professional competencies as they engage in action research. Teachers must be participants in educational research and development from their first education courses, through their professional development, and on to their service as mentors to new teacher... "We need research that helps the institutions and the people who work in them raise questions about their own goals and practice as part of their everyday work" (Bauman, 1996).

Along with other professional development activities such as accumulating experiences in teaching and educating students, self-learning, self-supplementing and updating of professional knowledge and skills involved..., action research can also be a helpful tool for teachers in the development of their profession. Doing action research helps teachers test the reality of his/her teaching, examining whether his impact on the teaching and learning subjects are really effective as expected. Continuing to identify problematic situations to learn and solve will help teachers to better understand the nature of educational phenomena, seeking more and more ways and means of impact. In addition, by sharing, reporting action research results to colleagues, school leaders and people who concerned, teacher can set up a self-assessment process for themselve and his colleagues. With scientific reasoning and clear collected data, it is scientific that teachers can express and solve the problems they are studying. Critical discussions in the peer review community (with colleagues and school leaders) will not only help the researcher/teacher better understand his or her work but will also help participants expand their knowledge and motivate everyone involved; and thus, the professional competencies of the whole team would be developed.

\section{Materials and Methods}

Consequently, the aim of this article is to reveal the possibilities of action research as a tool for teacher professional development in Vietnamese high schools. It also includes some 
further objectives:

- To specify the possibilities of the incorporation of action research - a form of educational research - into teacher professional development;

- To identify the state of Vietnamese teachers' competence in action research;

- To propose some orientations on promoting teacher professional development through developing action research skills in Vietnamese schools.

Methods applied in the article:

- Scientific literature analysis;

- The method of surveying, semi-structured intervewing;

- The method of statistical analysis which helped to systematize and generalize the results.

In order to obtain information about the current state of Vietnamese teachers' competence in action research, we conducted a scale-based assessment based on the designed criterion and indicators of the teachers' competence in action research. The instrument toolkit includes a questionnaire, a semi-structured interview, and analyzing teacher research reports. The sample consisted of 277 teachers and administrators from 3 provinces/cities of Vietnam: Hanoi, Quang Tri and Kontum.

\section{Results}

\subsection{Teacher Research - An Important Role in Vietnamese Teachers' Professional Development}

\subsubsection{Requirements on Vietnamese Teachers' Competences in Professional Development}

Teacher competences in professional development is one of the core competencies of the teacher competency standards. This system is considered to be the capacity to ensure the professional success of every teacher, as defined in the Professional Standards for Teachers in Vietnam and in many countries as well.

In Vietnam, the Professional Standards for Teachers were promulgated in 2007 (for elementary school teachers) and 2009 (for secondary teachers) by the Ministry of Education and Training. The requirements for the performance of professional activities in the basic areas for teachers at specific levels in this competency system includes: (1) Capacity to understand learners and the educational environment; (2) Capacity to develop and implement teaching plans; (3) Capacity to build and implement education plans; (4) Capacity to monitor and evaluate student achievement and moral education; and (5) Professional development capacity. In particular, criterion 6 on Professional development capacity, cites about capacity of self-assessment, self-learning and self-discipline; and capacity to identify and address issues that arise in practice in order to meet new requirements in education. With this explanation, the content of the teacher professional development capacity includes the nature of the teacher's educational research activity (Criterion 25). Thus, the professional development capacity along with the educational research capacity which cited in the teacher professional standards sets are either mutually exclusive or coincidental, and what are the core competencies of professional capacity system/pedagogical capacity of teachers. 
It is witnessing the current trends of educational innovations tending towards modern theoretical perspectives such as school curriculum development, differentiated instruction, integrated teaching, competency-based teaching, etc. When applied into schooling, these views require that teachers be well equipped with pedagogical knowledge and pedagogical skills to study, select, and design teaching forms, methods, means... suiting to their students. Moreover, educational research is a very good field for teachers to assert themselves. The capacity of teachers is expressed primarily through teaching and scientific research. Through participation in educational research, teachers are not only confirmed but also found limitations in their knowledge to timely supplement. It is important for every teacher to accomplish his or her duties.

Based on the importance of teacher educational research, the Ministry of Education and Training of Vietnam (MOET) has expressed his interest in the implementation of the annual educational mission that require local schools to improve the quality of professional activities of administrators and teachers. In the instruction document of the Secondary Education Mission for the 2014-2015 school year, the MOET cited that educational research must be seen as not only essential work for teachers but also for students: "Enhance teachers' capacity of educational research and promote activities of guidance for students in scientific research" (MOET, 2014).

\subsubsection{Teacher Research at High Schools in Vietnam}

The current trends in education are geared towards modern theoretical perspectives such as school curriculum development, distributed teaching, integrated teaching, and learner-centre teaching. These perspectives, when applied to high schools, requires teachers not only to be fully equipped with knowledge and pedagogical skills, but also to combine with scientific research to learn, select, design suitable structures, methods and means for their students.

In the field of education - training in general and teaching in particular, scientific research is a task, and an integral important part. Participating in educational research helps teachers expand their knowledge and expertise to be better in teaching. Furthermore, teachers' abilities are proven by scientific research. The professional capacity of the teacher is expressed primarily through teaching and scientific research. Within scientific research, teachers identify limitations in their knowledge to improve.

In Vietnam, basic scientific research of high school teachers which derived from their individual needs in their narrow specific field (Mathematics, Informatics, Physics, Chemistry, Biology, Literature and History, Geography...) usually appear under publications in specialized journals or guidance and counseling for students about doing scientific and technological research to participate in science and technology competitions. The traditional form of teachers' participation in the educational research has been called as initiative writing which has been considered as an individual research activity. This kind of research's contents mostly focused on innovation in educational management, innovation in educational methods, development and fostering teachers, socialization of education, innovating contents, programs and textbooks, renovating examination and evaluation of educational outcomes. In fact, initiative writing is not an activity of doing research, but rather a research methodology 
which is called a method of summing up experience. Therefore, if it is actually an initiative writing (with its ideal implement the nature of summarizing experience), it has not been acknowledged as a scientific research. It is necessary and sufficient that in the process of conducting research, teachers must find out specific problem that needs to be solved in their working environment, and then develop a study plan to conduct the study towards the study's aim. These are basic steps of doing research. In words, writing experiential ideas is not an activity of doing research.

\subsection{Vietnamese Teachers' Competences on Action Research}

To understand the current state of teachers' research skills, we conducted an assessment based on the aspects, criteria and indicators of the High School Teachers' Research Skill system (note 1). The teachers participating in the survey self-assess their capacity at specific levels in each indicator. The sample consisted of 277 teachers and administrators of high schools (230 teachers and managers) and junior high schools (47 teachers and managers) in 3 provinces/city: Hanoi, Quang Tri and Kontum. Combined with practical research methods such as group discuss, interviews and retrospective of related materials, the following results were obtained:

\subsubsection{Knowledge of Educational Research}

In general, teachers' self-assessment about their knowledge of educational research were at above average level, with no content scoring at 4 (which is equivalent to the "good" level in the scale). In particular, the content of "benefits of educational research" was the lowest, while all the remaining content within this criterion was not much different. However, this number seemed to be inaccurate, as most of the participants showed the lack of basic knowledge about research skills in the in-depth interviews.

\subsubsection{Conducting Educational Research Skills}

Table 1 shows that teachers' self-assessment about their educational research skills was at a relatively low level (equivalent to "weak" in the scale). Highly rated content included: "Searching for relevant information; collecting and systematizing documents for research from various sources such as books, newspapers, scientific journals, sources from the Internet "; "Identifying topic, research aims, participants accurately"; "Having experience for yourself and sharing with colleagues who share the same interest in the research "; "Positively, proactively share, discuss with members of the research community, colleagues and interested persons (researchers, consultants, donors ...)". Teachers evaluate the following contents at a lower level: "Writing papers and publishing on educational academic journals "; "Writing report about the results and present at educational conferences, workshops "; " Writing report about the results and sharing on educational forums"; "Design of measurements, scales for collecting impact study data"; "Developing human resource, review panel".

The results from this self-assessment and the interviews shared a relatively accurate reflection of the current situation of the capacity of teachers' research skills. Most teachers admitted that they were not equipped and trained about these skills. They stated that while actively seeking 
information to support research, identifying critical and urgent issues in their own teaching and learning practices, the process of conducting research was difficult, especially the steps involved in data collection and reporting as well as publication of research results.

Table 1. Self-assessment of teachers about educational research skills

\begin{tabular}{|c|c|c|}
\hline Skills & Mean & $\begin{array}{l}\text { Standard } \\
\text { Deciation }\end{array}$ \\
\hline Recognizing the research problems from teaching and training students & 2.85 & 1.041 \\
\hline $\begin{array}{l}\text { Positively, proactively share, discuss with members of the research community, colleagues } \\
\text { and interested persons (researchers, consultants, donors ..) }\end{array}$ & 2.82 & .899 \\
\hline Identifying research question/research problems accurately and meaningful & 2.73 & .932 \\
\hline Identifying reasons of the research problems accurately and completely & 2.70 & .946 \\
\hline Forming ideas for intervention and selecting appropriate impact for research & 2.60 & .997 \\
\hline Creating hypotheses accurately & 2.71 & 2.629 \\
\hline $\begin{array}{l}\text { Searching for relevant information: collecting and systematizing documents for research from } \\
\text { various sources: books, newspapers, scientific journals, sources from the Internet }\end{array}$ & 2.92 & .952 \\
\hline Analyzing and evaluating collected information & 2.72 & .840 \\
\hline Being able in data analyzing skills, quantitative and qualitative research & 2.62 & .937 \\
\hline Writing literature review logically and completely & 2.66 & .928 \\
\hline Identifying topic, research aims, participants accurately & 2.92 & 1.034 \\
\hline Choosing appropriate research methods & 2.80 & 1.032 \\
\hline Choosing reasonable sample size scientifically & 2.73 & .952 \\
\hline $\begin{array}{l}\text { Fully identifying and mobilizing appropriate research resources, promoting high interactivity } \\
\text { in the relationship between teachers-teachers, teachers-parents, teachers-managers.... }\end{array}$ & 2.63 & .899 \\
\hline Developing human resource, review panel & 2.49 & .944 \\
\hline Conducting appropriate intervention in appropriate time and ensuring research ethics & 2.64 & .914 \\
\hline Observing the intervention process and adjust when needed & 2.56 & .894 \\
\hline Being able to design scales, questionnaires to collect data (pre-test, post-test) & 2.48 & .989 \\
\hline Being able to use analysis software, quantitative assessment. & 2.52 & 1.045 \\
\hline Being able to use analytical techniques, quantitative and qualitative assessment of the results & $\mathrm{u}$ & .969 \\
\hline Finalizing the research report scientifically and logically & 2.77 & .939 \\
\hline Describing persuasively the impact of the study & 2.74 & .912 \\
\hline $\begin{array}{l}\text { Positive listening and answering completely, accurately about the research from the review } \\
\text { panel }\end{array}$ & 2.77 & 1.007 \\
\hline $\begin{array}{l}\text { Having experience for yourself and sharing with colleagues who share the same interest in the } \\
\text { research }\end{array}$ & 2.81 & .965 \\
\hline Identifying coming related research problems after the intervention & 2.75 & .928 \\
\hline Applying research results into educational practice & 2.77 & .982 \\
\hline Sharing and guiding colleagues to apply research results into educational practice & 2.69 & .970 \\
\hline Writing report about the results and sharing on educational forums & 2.36 & 1.071 \\
\hline Writing report about the results and present at educational conferences, workshops & 2.28 & 1.076 \\
\hline Writing papers and publishing on educational academic journals & 2.14 & 1.077 \\
\hline
\end{tabular}




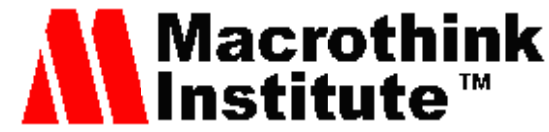

\subsubsection{Experience in Conducting Educational Research}

Of the 277 surveyed teachers, the number of teachers who did not undertake any educational research accounted for $26.7 \%$. This indicated that more than a quarter of teachers currently have no practical experience in educational research. By the same token, about $20 \%$ of teachers said they were in the planning stages of a study that was due to take place in the near future.

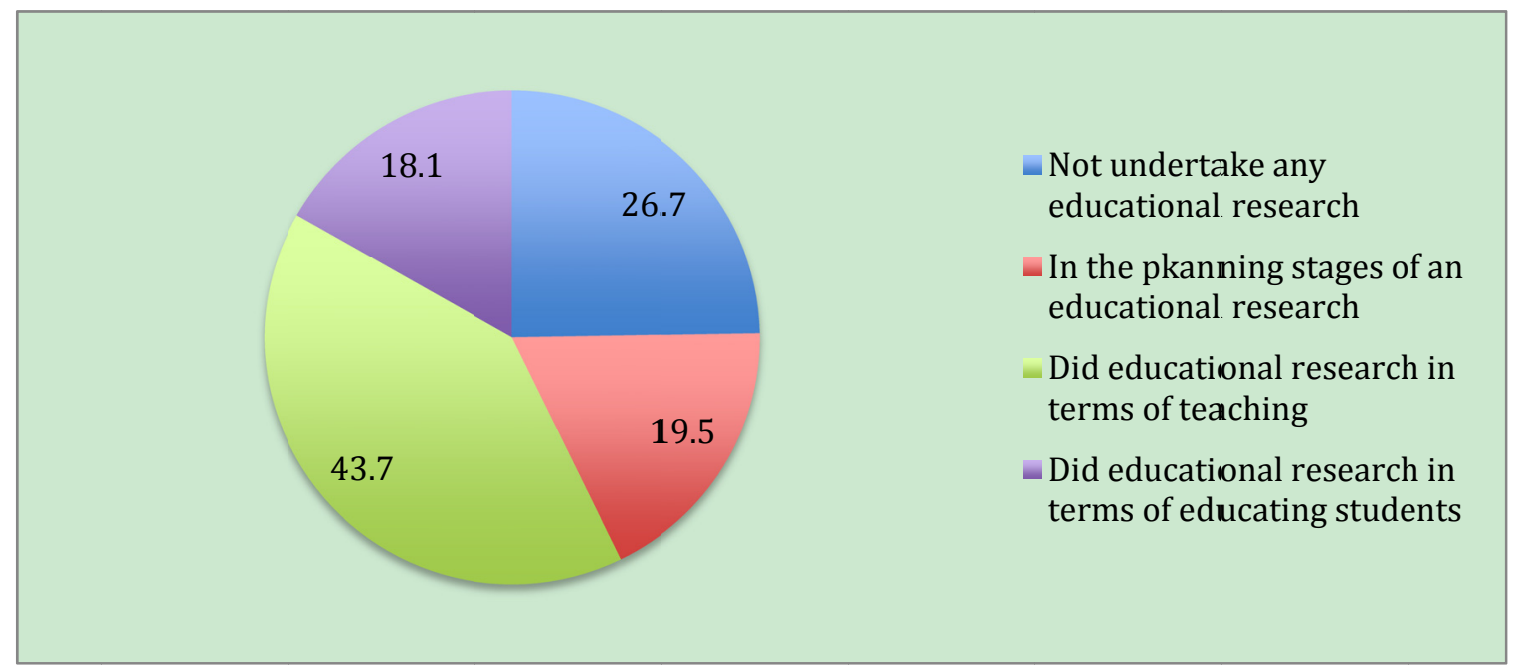

Figure 1. Teachers' experience in conducting educational research

On the other hand, the percentage of teachers who have done one or more academic research projects, applied their research to teaching was $43.7 \%$ while to student education accounted for only $18.1 \%$. This percentage indicated the needs for innovation in higher education. The cause according to teachers was that applying to teaching activities are much straightforward than to education as its clearer and quicker results, meanwhile education needs a long process of impact and the results will take time to be appreciated.

In general, beyond the basic knowledge of applied pedagogical research which was trained by different educational associations (Ministry, Faculty, Department, and School), teachers were lack of practical experience related to research activities. The science of educational research is a form of action research, it is essential for the teacher to experience the process of changing teaching and education. Without experience, the distance between theoretical to practical and the target to the results would not be approached.

\subsubsection{Attitudes and Values in Conducting Educational Research}

Regarding the attitude in educational research which was included in the interviews, the results revealed that most teachers and administrators were not fully aware of the ethical requirements in conducting research which was limited to plagiarism. Some common ethical issues that teachers had made were asking for parent/guardian permission for their children to participate in research, ensuring the confidentiality of the participants' information, 
possession and co-ownership, responsibility for the research's quality and the effectiveness of research results to the educational practice.

In terms of the attitude of reforming the practice of teaching and education, majority of teachers conduct educational research to deal with the criteria for educational performance ranking and excellent teacher competition which lead to the limitation in renovating their teaching and learning. D. H. H. - a Technology teacher and a Secretary of the Ho Chi Minh Communist Youth Union at N. T. high School said, "I, like my colleagues, are working to legalize emulation conditions, but the desire to change teaching methodology or educational practices. We do for ranking without any applications. Conducting research to improve reality must come from enthusiasm and passion that I have not seen anyone".

\subsection{Orientations on Improving Teacher Competence on Professional Development through Developing Action Research Skills}

The findings indicate that: (1) The capacity level of the teachers in conducting educational research in general and scientific research of improvement practical in particular was lower than average; (2) The needs of teachers and administrators at high schools for the improvement of research capacity in innovating reality were very high; (3) Fostering the capacity of educational research in general and the impact of renovation teaching reality in particular was inadequate at all levels. Inadequate and ineffective training courses were unable to improve the capacity in conducting research for teachers; (4) Self-reliance of teachers was a problem as their unawareness of the importance of educational research activities for their professional development as well as the quality of teaching and education.

In this context, some orientations for solutions are proposed to improve teacher competence on professional development through developing their action research skills, as follows:

Firstly, it is necessary to set up a curriculum for in-service training teachers in action research, including specific tasks such as: Determining the content of training programs; Developing a training plan; Providing facilities and resources for training...

Secondly, it is necessary to enhance teacher's action research through research activities at school, with particular emphasis on measures including: Promote research into the impact of improving the practice in professional activities (focus on the role of the professional team in the organization, monitoring and evaluation of performance); Establishment of a cooperative network, support for research on the effects of practical renovation in each school and groups of local schools; Development of a learning resource system, exchange, discussion, teacher support in the study of practical improvement impact...

Thirdly, it is necessary to renovate the management mechanism of the educational research activities for teachers with the following basic steps: raising the capacity of scientific research for teacher students in the teacher education programs; Promoting the organization of fostering plans at all levels, support and create incentives for schools to organize their action research to suit the conditions and demands of each school; Promulgating regulations on support and facilitation of teachers' participation in researches, practical improvement measures (time, funding, infrastructure, information network, assisting teachers to publish 
research results Studying in specialized journals or specialized seminars...).

Fourthly, it is necessary to renovate the mechanism for evaluating the educational science research activities for teachers in general, including: setting standards for evaluating the results of teacher action research (with specific indicators) so that teachers can also be used as reference materials, the direction of their research; Formal assessment of conformity, objectivity, even cross-evaluation, private assessment ...; Build a contingent of assessors with knowledge, experience and skills related to the study of the practical improvement impact from the central to local levels (effective combination of education administrators, communication and university lecturers); Make a plan for monitoring, reviewing the publication, sharing and application of research results at schools...

\section{Conclusion and Discussion}

The quality of general education system depends greatly on the professional competence of the teacher. As part of the career development capacity, educational research capacity is not only a criterion of the professional standard required of any teacher, but it will also help the teacher - as an educator - can find out the problems that need to be solved in their working environment, develop a plan for researching that issue, organize the impact/intervene/change the current and future situation. It also contributes to improving the quality of teaching and learning in schools. It is witnessed that the capacity of educational research of school teachers in Vietnam is still not high, even the majority of teachers only perform because they are required, not from their own needs. There is a great lack of knowledge, skills, attitudes, and beliefs about action research.

\section{References}

Joseph, W. C., \& Russell, K. S. (2011). Research Methods in Education. SAGE Publications.

Kemmis, \& Mc Taggart. (1992). The Action Research Planner (2nd ed.). Geelong, Victoria: Deakin University Press. In Louis Cohen, Lawrence Manion \& Keith Morrison. Research methods in Education. London and New York: Routledge.

Emily, E., \& Anne, B. (2016). Language teacher action research: achieving sustainability. ELT Journal, 70(1), 6-15. https://doi.org/10.1093/elt/ccv060

Elliot, (1991). Action research for Educational Change. Open University Press, Bristol, PA.

Nguyen Thi Kim Dung. (2015). Teacher education towards the orientation of forming professional competences for teacher students in Vietnamese universities of education. HNUE publisher house.

David, C. J. (2014). Professional Development: An Effective Research-Based Model. Retrieved December 12, 2017, from https://pdfs.semanticscholar.org/4cf3/27e69351d4213481b6dca703a5212fc2f0c0.pdf

Cabaroglu, N. (2014). Re-Visiting the Theory and Practice Gap through the Lens of Student Teacher Dilemmas. Australian Journal of Teacher Education, 39(2). http://dx.doi.org/10.14221/ajte.2014v39n2.10 


\section{Macrothink}

International Research in Education

ISSN 2327-5499 2018, Vol. 6, No. 2

Gray, J., \& Campbell-Evans, G. (2002). Beginning Teachers as Teacher-Researchers. Australian Journal of Teacher Education, 27(1). http://dx.doi.org/10.14221/ajte.2002v27n1.4

Bauman, J. (1996). Conflict or compatibility in classroom inquiry? One teacher's struggle to balance teaching and research. Educational Researcher, 25(4), 29-35. http://dx.doi.org/10.2307/1176522

MOET. (2014). Guidance document of the Secondary Education Mission for the 2014-2015 school year.

Leeman, Y., \& Wardekker, W. (2014). Teacher Research and the Aims of Education. Teachers and Teaching: Theory and Practice, 20(1), 45-58. https://doi.org/10.1080/13540602.2013. 848516

\section{Notes}

Note 1. The scale was the product of Vietnaese national project "Improving capacity of research skills for high school teachers in the approach of improving the practice" (Project Code: B2014-17-55).

\section{Copyright Disclaimer}

Copyright reserved by the authors.

This article is an open-access article distributed under the terms and conditions of the Creative Commons Attribution license (http://creativecommons.org/licenses/by/3.0/). 